\title{
Nursing Students' Notions about Palliative Care Bogota D.C. 2016
}

\section{Miguel Antonio Sánchez Cárdenas, Victoria Eugenia Cabal Escandón, Ruth Valle Ballesteros}

Faculty of Nursing, El Bosque University, Bogota, Colombia

Email: sanchezcmiguel@unbosque.edu.co

How to cite this paper: Cárdenas, M.A.S., Escandón, V.E.C. and Ballesteros, R.V. (2018) Nursing Students' Notions about Palliative Care Bogota D.C. 2016. Journal of Biosciences and Medicines, 6, 15-30. https://doi.org/10.4236/jbm.2018.68002

Received: June 14, 2018

Accepted: July 31, 2018

Published: August 2, 2018

Copyright (c) 2018 by authors and Scientific Research Publishing Inc. This work is licensed under the Creative Commons Attribution International License (CC BY 4.0).

http://creativecommons.org/licenses/by/4.0/

\section{cc) (†) Open Access}

\begin{abstract}
Training in palliative care is a necessity for health care systems. Nursing education should guarantee the development of basic skills in this field of health care. The objective of the study is to explore the notions about palliative care of a group of students from a nursing institute, in the light of the skills established by the Colombian Network of Education in Palliative Care. The method used is a qualitative one, using the analysis of narratives as a research tool in the classroom. The results allow us to infer that the students rely on notions about palliative care in some subject areas, without being able to consolidate an understanding that allows the integral intervention in people with palliative needs. It is necessary to reinforce the training process for symptom control, spirituality, and the organization of palliative care within the health care system.
\end{abstract}

\section{Keywords}

Competency-Based Education, Palliative Care, Students, Nursing

\section{Introduction}

Palliative care lists a set of activities and own knowledge of the disciplines that take up the care of the patient and the family with advanced and/or terminal diseases, for which it is necessary to recognize the conceptual elements of the differential approach, the focus on the patient, the different notions of life and death, as well as the ethical implications that belong to the practice. Palliative care transcends the boundary of oncological disease, with symptom controls being under its field in the final phase of cases such as the acquired immunodeficiency syndrome, chronic obstructive pulmonary disease, heart failure, chronic liver disease, Alzheimer's disease, degenerative neurological diseases and the 
handling of people with functional limitations and/or challenging mobility [1].

Nursing in palliative care should respond to the evolving incidences of the disease through the control of symptoms, help with basic needs, collaborate in the planning of everyday life, provide an adaptation process and basic emotional support, contribute to the patient-family-team communication, respect values, beliefs and ways of life, educate the family on specific aspects of care and assist with potentially involved resources [2].

To Stjernswärd (2007), education in palliative care is a necessity for health care systems which is a dimension of public health, for which this author states that all health professionals should have the basic knowledge and skills in this area of expertise, to encourage the early and appropriate handling of the common symptoms and problems in patients with an advanced disease. Nursing professionals require training in the area of palliative care for the purpose of improving the quality of care provision, access to the provision of services and the development of palliative care in the country [3].

In 2015, the Colombian Network in Education of Palliative Care (Redcoledupal) constructed the skills training in palliative care for undergraduates in medicine, nursing and psychology, in order to strengthen the education in palliative care at a national level through the joint work of professionals and organizations committed to its development. This study sets out to explore the notions of palliative care of a group of students in a nursing institute, in the light of the skills established by this academic network.

Redcoledupal defined a total of 26 skills grouped into subject areas and determined the allotted time in a proportional manner; this information corresponds to: definitions and values of palliative care (5\%); identification and management of symptoms (40\%); psychosocial and spiritual aspects (20\%); communication in palliative care (15\%); ethical and legal aspects of palliative care (5\%); teamwork and personal reflection (5\%) and implementation of palliative care services (10\%).

\section{Method}

The following paper arises from the need to identify if undergraduates have notions of palliative care related to the skills in order to work in this area of health, for which it assumes the research in the classroom as a methodology, accepting, as it is posed by Restrepo (2009) [4], that there are three approaches for its development: "the teacher's research about his practice, the teacher's research about the student's practices and the research in which the teacher follows the student's investigative processes".

The work is carried out with the second approach, in which the teacher values the work done by the students. It leads them to think about the learning and take in what is observed to guide the decision making that allows him to provide feedback on his endeavor and establish improvement opportunities for the teaching process. So if the teacher's work is considered research in the class- 
room, the teacher must follow a method in which he makes a collection of classroom information, develop a work interpretation and analysis of the student's contributions and acts according to the identified findings [4].

The researchers of this study are the teachers of the program that the students are part of, which allows them a preliminary understanding of the particular characteristics of the group and to plan important pedagogical strategies based on a reflection of knowledge in palliative care. At the time of implementation, the students were starting the $\mathrm{X}$ academic semester of a program that is not contemplated in their studies plan, specific training in palliative care; for the development of the activities, the students were divided into seven subgroups of 4 - 5 participants, formed voluntarily. Following the ethical standards of the classroom investigation, the students were informed about the purpose of this study and the usefulness of the gathered information.

In each of the groups the spontaneous participation of the students was allowed, the material required for the development of each activity was given, as well as the instructions for the work in each subject area. The general guidelines established by the researchers were: 1) Timeliness in meeting the allotted time; 2) No use of electronic devices or reference sources in order to obtain narratives that are products of the reflection and not of searches made during the session; 3) Actively participate in the development of the exercises, which allows the joint construction of notions, and 4) Possibility to record "The elements for the analysis of the subject area are missing".

For all the selected strategies a record format was established, which allowed the collection of the reflections and narratives constructed by the students. This approach responds to the research methods in the classroom, which use narrative as a natural mediation between the students and the teacher in all schools in the western world [5]. In this context, the narrative constructed by the students allows the spontaneous expression of each of the addressed subject area notions. For the qualitative analysis of the data, ATLAS TI version 7.0 was used, making a descriptive analysis of the information collected.

The report allows in its first part the records of the central aspects of the group's discussion, taking into account that the latter is set up according to a pedagogical knowledge of the contents, learning first and foremost by talking and working with peers. In the second part, the students recount the agreed aspects for socialization, based on a consensus methodology, considering that the narrative models allow peers to support each other to understand and construct notions [5].

For Löfström and partners (2015) [5] when the narrative forms are used an effect is assigned to the events and they are given coherence, integrity, extent and conclusion, which represents in the investigation the possibility to infer what the notions about palliative care constructed by students of the $\mathrm{X}$ semester of a Nursing Institute are and identify the strengths and consolidation opportunities of the knowledge about palliative care from the following activities (Table 1). 
Table 1. Academic work plan in the classroom.

\begin{tabular}{|c|c|c|c|}
\hline Subject area & $\begin{array}{l}\text { Allotted time } \\
\qquad(\min )\end{array}$ & Purpose of the activity & Working strategy \\
\hline $\begin{array}{l}\text { Definition and principles of } \\
\text { palliative care }\end{array}$ & $35 \mathrm{~min}$ & $\begin{array}{l}\text { From individual reflection, identify the notions } \\
\text { that the students have about palliative care drawn } \\
\text { from two analysis units }\end{array}$ & $\begin{array}{l}\text { "Suffering" and "Palliative Care" were selected } \\
\text { as analysis units. Three groups worked on } \\
\text { "suffering" and the remaining four on "palliative } \\
\text { care". Each group had to select phrases or words } \\
\text { that clearly represent the analysis unit }\end{array}$ \\
\hline $\begin{array}{l}\text { Psychosocial aspects and } \\
\text { support networks }\end{array}$ & $65 \mathrm{~min}$ & $\begin{array}{l}\text { Explore notions about support networks, } \\
\text { spirituality and family approach in palliative care }\end{array}$ & Case report and analysis \\
\hline Communication in PC & $60 \mathrm{~min}$ & $\begin{array}{l}\text { Recognize the student's capacity to communicate } \\
\text { bad news to the patient, the caregiver and the } \\
\text { family }\end{array}$ & $\begin{array}{l}\text { Development of seven role games: imminent } \\
\text { death; transfer to home with instrumental } \\
\text { activities; alternative therapies at the end of life; } \\
\text { urgent hospitalization re-entry due to } \\
\text { uncontrolled symptoms; palliative sedation; } \\
\text { denial to palliative care; and diagnostic } \\
\text { certainty }\end{array}$ \\
\hline $\begin{array}{l}\text { Identification and } \\
\text { management of symptoms }\end{array}$ & $215 \mathrm{~min}$ & $\begin{array}{l}\text { Recognize the understandings of the symptoms } \\
\text { that represent palliative needs, their means of } \\
\text { assessment, possible interventions and evaluation } \\
\text { of the health outcome }\end{array}$ & Reports A and B billboard activities \\
\hline $\begin{array}{l}\text { Identification of capabilities } \\
\text { to take on specific skills }\end{array}$ & $30 \mathrm{~min}$ & $\begin{array}{l}\text { Identify skills for which the students consider they } \\
\text { have the capacity to take on }\end{array}$ & $\begin{array}{l}\text { Analysis of disciplinary skills and select those } \\
\text { they consider to have the capacity to develop }\end{array}$ \\
\hline
\end{tabular}

\section{Results and Discussion}

For the work's development we counted on the participation of 31 students, all belonging to a nursing program at a university in Bogotá. The participants have an average age of 22 years, mostly female (26 students), who have completed 171 academic credits of the 190 credits from the curriculum, corresponding to subjects that do not address specific content on palliative care.

\subsection{Definition and Principles of Palliative Care}

In this subject area the skills related with the definition of palliative care, its philosophy and basic principles are addressed, the concept of hospices and the foundation of nursing interventions in disciplinary conceptual models. In the analysis of the narratives, it is shown that the students construct some constituent elements of suffering, such as "pain regarding a situation", "mental and physical unbalance" and "circumstantial crisis". Similarly, they elaborate as constituent elements of palliative care: "quality care", "humanized care", "accompanying the patient and his family in the end phase", "diminishing pain, suffering, and agony".

The participant's narratives show that they have elements to construct a definition of both palliative care as well as suffering, as seen in the following statements:

"Palliative care: Is the way of providing quality care to improve the way of dealing with any disease, reduce or mitigate some effects of the disease in terms of physical, mental, emotional, social and spiritual health" Group 6. 
"Human suffering. physical and mental unbalance that leads to a crisis that directly affects a person's quality of life and that of his family, and stems from an unexpected situation" Group 1.

Once these notions are confronted with the definition from the World Health Organization (WHO) that recognizes palliative care as "an approach that improves the quality of life of patients and families that are facing problems associated with life-threatening diseases, through the prevention and relief of suffering by making an early identification, an appropriate evaluation and applying treatments for pain and other physical, psychosocial and spiritual problems" [6], it is noted that the participating group recognizes a large part of the elements that make up WHO's definition. Regarding the prevention of suffering and the provision of palliative care to people with a non-oncological disease, they are not described in the narratives of the students.

The narratives made by the different groups do not describe the concept of hospices nor the founding of the nursing interventions in the disciplinary conceptual models. It is considered necessary that undergraduates of a nursing program recognize the hospices philosophy, given the implications that this has in providing services to patients with palliative needs.

\subsection{Ethical and Legal Aspects}

In the undergraduate education of the participants there are three covered subjects regarding education in bioethics, two subjects about nursing law and transversal education on the Colombian health regulations. For the development of the activity, an analysis of the case was posed, in the narration the situation of a person with advanced cancer in the process of functional decline is described, who verbally expressed their wishes about limiting the therapeutic efforts in case of an advanced disease. The substitutes to make the decision are his two sons (given that he currently has delirium), who against a urinary tract infection are faced with the decision to transfer him to a hospital with handling in a nursing home where the patient resides. Faced with these approaches the participant group indicated choosing an option that they would take as part of the palliative care team, exposing ethical and legal arguments to support the decision.

According to what was described, the participants consider three options, the first is to offer palliative care in the nursing home were the patient resides; transfer to the hospital for the handling of the acute condition and a subsequent palliative approach; and provide information to the sons so that they are the ones to make a decision about the transfer. Regarding the first alternative, the participants state that the most appropriate decision is to start the palliative management in the person's place of residence in consideration of the verbal request for limitation of the therapeutic effort, which despite of not being written is a free and informed manifestation of the will of the patient. On the other hand, the potential risks involved with the hospitalization of the patient are presented as they are described by groups four and six in their narra- 
tive.

“(...) we consider that the person should start a home palliative care, taking into consideration the ethical principle of autonomy and beneficence" Group 4.

"Besides this, it is considered a risk to transfer him to a hospital because it increases factors that could aggravate his situation" Group 6.

Against the alternative of transferring him to a hospital for the handling of the acute condition and a subsequent palliative approach, the group that considers this option argues the relevance of the transfer due to the described health situation, even when in the presented case the prognostic scales that suggest a final phase of life are stated. Some of the proposed considerations are reflected in the following text:

“(...) treat the patient in his residence, after a hospital intervention, assessing whether or not he meets the requirements for home care, example: primary caregiver, health conditions, etc" Group 3.

Despite being instructed to select a management option, two of the participant groups considered that the best alternative of approach was to inform the patient's sons about the benefits to bear the disease and the disadvantages of the options that were presented in the case. One of the arguments is stated below:

"Based on the bioethical principles (no maleficence, beneficence, justice and autonomy) we arrived to the conclusion that after evaluating the clinical condition of the user, a consensus should be formed among the patient's sons" Group 2.

\subsection{Psychosocial Aspects and Support Networks}

A case study presented to the participants narrates the different social and familiar situations of a patient with advanced liver disease without the possibility of a decisive approach, expressing his interest of dying alone. The participants were to identify how the meaning of spirituality is presented, coping with imminent death, who assumes the role of caregiver and document five findings related to the fatigue of the caregiver and/or family claudication, as well as to identify the support networks of the patient and the family. In light of this, the participants identified the figure of the family caregiver, in which six of the seven groups, recognize findings associated with the fatigue of the caregiver, including the indicated characteristics related to the caregiver (e.g. the caregiver's age), with situational factors (e.g. the patient's resistance to the treatment), the perception of the burden of care (e.g. long term situations) and care skills (e.g. lack of training in the instrumental care of the person) [7].

For Borneman and partners (2015) [8] the concept of "family claudication" is approached specifically in the field of chronic disease, so it is common to find that undergraduate nursing students associate it with family dysfunction and work for its prevention and management, however of the seven participant groups, three expressed not having the elements to perform the analysis. One group did not answer and the three remaining presented arguments that do not 
relate to the concept of family claudication, as shown in the following narrative:

"Family claudication is when families agree to leave legal matters and the funeral preferences" Group 3.

When approaching the concept of spirituality, which is getting stronger in nursing education, due to the changes of the social paradigms and the emerging practices of spiritual philosophy that legitimize the relationship of body, mind and spirit in the subject of care as a model of integration [9], the narratives of the participants do not show an appropriation of the spiritual component in the process of care to the individual with palliative needs.

\subsection{Communication in Palliative Care}

Redcoledupal recognizes two skills in this domain for the nursing professional that relate to the development of communication skills for bad news and the possibility of identifying the responsibilities in communication with the people who require palliative care and their families. The development of role play games allowed the research group to establish a third domain related with the perception of the characteristics of a nursing professional that communicates with people who have palliative needs.

In their narratives the students construct a nursing professional who is calm, expressive, and comprehensive with the condition of the patient and his family, with postgraduate training and experience in the area. Such as, it is evidenced in the narratives of groups 1 and 7.

" $A$ young woman who is calm, expressive and comprehensive before the condition of the patient and his family" Group 1.

"Professional specialized in palliative care and has been in the oncology operation for 3 years" Group 7.

In the student's narratives, it is recorded that for the development of communication skills for bad news, it is necessary to have skills to inform others about the futility of the treatment, the outcome of a situation, how to deal with situations involving the end of life and the importance of establishing points regarding the handling of palliative care. Likewise, the students consider that the communication responsibilities are related to the need to explain what palliative care is, the information about the procedures and interventions, the importance of exposing the grounds on which the decisions will be made and to explain effects and consequences of the decisions made.

\subsection{Identification and Management of Symptoms}

The subjective reference that a sick person gives of the perception or change recognized as abnormal is known as a symptom, caused by a pathological condition, being a useful warning of an alteration of mental, physical or social health

or a combination of the three [10]. According to the views expressed in the theory of unpleasant symptoms, each symptom is conceptualized as a multidi- 
mensional experience that can be quantified in common dimensions: intensity (strength and severity), coordination (duration and frequency of occurrence), perceived level of distress (level of discomfort and pain), and quality [11].

In this sense, the subject area of the research work was divided into two parts (A and B), in session A, each group stated the symptoms that a person with palliative needs may experience. The brainstorm technique was used for the activity, giving a time limit of two minutes. The results showed that the students recognize symptoms in two of the three dimensions described in the theory of unpleasant symptoms. The following Table 2 shows the distribution of the symptoms recognized by the students:

About the social dimension, none of the groups recognize conditions such as the caregiver's suffering or the family claudication as unpleasant symptoms, for which a palliative care approach should be followed. It is possible to infer from this activity, the emphasis towards the physical symptoms, mainly pain, nausea and dyspnea. However, the participants of the study do not mention symptoms of high prevalence in the person with palliative needs, such as constipation, diarrhea, intestinal obstruction or ascites.

As for psychological symptoms, poor recognition of alterations in mental functions is shown, since they do not mention conditions such as insomnia, confusion or delirium. Only one group of students recognizes depression, anxiety and fear, drawing attention due to the impact of these symptoms on the family and the patient at the end of life.

In session $\mathrm{B}$, each one of the groups had to identify the way of assessing potential nursing interventions and the evaluation of achieving the intervention objective for specific assigned symptoms. The information reported by the participants is shown in Table 3.

The analysis that the authors make about the nursing evaluations, the planned interventions and the evaluation of the interventions is presented below.

The nursing evaluation is a tool that varies depending on the clinical context, without there being any doubts regarding its importance in the provision of high quality care [12].

In palliative care the evaluation is focused on the symptom as a multidimensional experience that can be evaluated as an entity in itself. For the participants, the evaluation of the symptoms contemplated in the activity is guided towards the physical and mental exam according to the specificity of the symptom, in other words, that in the analyzed records there are no shown aspects of the mental sphere for the physical symptoms, nor are the physical assessments considered for symptoms at a psychological level.

It is possible to infer from the analyzed records that the students have notions to perform the symptoms evaluation. Only in the case of lymphedema did they report not having elements for evaluation. It is highlighted that the groups focus their evaluation on the pathological base condition of the patient, without recognizing that the symptom is a palliative need that deserves to be addressed on 
Table 2. Definition of unpleasant symptoms in palliative care.

\begin{tabular}{|c|c|}
\hline \multicolumn{2}{|r|}{ Physical symptoms } \\
\hline Pain & All groups recognize pain as a symptom. Two of the groups specifically mention headaches \\
\hline Dyspnea & $\begin{array}{l}\text { The seven groups identify alterations in the respiratory function as a symptom; three of them refer to the symptom } \\
\text { as dyspnea, two as a suffocation feeling and one as respiratory distress }\end{array}$ \\
\hline $\begin{array}{l}\text { Nausea, dizziness } \\
\text { and vomiting }\end{array}$ & All groups recognize nausea, six of them refer to dizziness as a symptom and one group states vomiting \\
\hline Paresthesia and tingling & $\begin{array}{l}\text { Three of the groups identify alterations in the peripheral vascular system or peripheral nervous, amongst them the } \\
\text { tingling, paresthesia and numbness }\end{array}$ \\
\hline Adenoma & $\begin{array}{l}\text { Regarding the loss of energy, each of the following symptoms was identified by a different group of students: ade- } \\
\text { nomas, despair, weakness, fatigue; two groups of students recognize fatigue as a symptom }\end{array}$ \\
\hline $\begin{array}{l}\text { Diarrhea, anorexia, } \\
\text { constipation, xerostomia, } \\
\text { itching and vertigo }\end{array}$ & $\begin{array}{l}\text { The stated conditions form prevalent symptoms in palliative care, however, they are identified by one or two of the } \\
\text { participating groups }\end{array}$ \\
\hline Others & $\begin{array}{l}\text { The groups of students recognize, as symptoms of palliative care, some in general nature, for example: blurred } \\
\text { vision ( } 3 \text { groups), tinnitus and paresis ( } 2 \text { groups), tremors, tightness and burning in the pit of the stomach } \\
\text { (1 group) }\end{array}$ \\
\hline \multicolumn{2}{|r|}{ Psychological symptoms } \\
\hline Disturbances in affection & $\begin{array}{l}\text { Symptoms related with affection disorders due to increased tone, specifically phobia, fear and anxiety, each one was } \\
\text { recognized by a different group of students }\end{array}$ \\
\hline $\begin{array}{l}\text { Depression and } \\
\text { disorientation }\end{array}$ & Each one of these conditions is recognized by a group \\
\hline Others & One group recognizes stress and another the emotional liability as symptoms in palliative care \\
\hline
\end{tabular}

its own. The diversity of reasons that cause the symptom is not identified, nor is the care visualized as long as it is not determined if the symptom is expected in the process of functional decline or if it is a symptom that should alert the physician to establish measures that aim to improve the patient's quality of life.

About nursing interventions considered as treatment, based on the knowledge and clinical judgment which a nursing professional performs to favor the outcome expected by the patient [13], the participant's records allow us to deduce that the interventions do not reflect the level of attained knowledge of the subject of care through the evaluation made, since it is observed that the students make a detailed collection of information, which they do not take into account for intervention planning.

The records show that for physical symptoms, interdisciplinary work is not stated, nor with the support networks; in contrast to what is recorded for the symptoms in the mental sphere, where the need of collaborative work with other palliative care team members and with the support network of the patient and his family is evident. Similarly, the pharmacological interventions are not clearly identified as a nursing activity in palliative care and the education of the family and the patient about the handling of instrumental care is not recognized as a nursing intervention, introduced by the palliative care team for the control of unpleasant symptoms, in order to improve the patient's quality of life and the arrival of death in a calm manner. 
Table 3. Nursing process of the unpleasant symptom in palliative care.

\begin{tabular}{|c|c|c|c|}
\hline Symptom & Form of evaluation & Possible Nursing interventions, & $\begin{array}{l}\text { Evaluation of achieving the objective } \\
\text { of the intervention, }\end{array}$ \\
\hline Pain & $\begin{array}{l}\text { Conduct a physical exam and complete } \\
\text { medical history, taking into consideration } \\
\text { vital signs, bearing and attitude, pain } \\
\text { assessment scales and verbal or gesture } \\
\text { expressions of the patient }\end{array}$ & $\begin{array}{l}\text { Analgesia as needed; taking vital } \\
\text { signs; reassess the pain scale and } \\
\text { implement alternative treatments, } \\
\text { taking into account the culture and } \\
\text { beliefs of the family and the } \\
\text { patient; The use of the analgesic } \\
\text { ladder of the World Health } \\
\text { Organization is recognized as a } \\
\text { tool for pain } \\
\text { control }\end{array}$ & $\begin{array}{l}\text { Assessment and anamnesis, taking } \\
\text { vital signs, bearing and attitude } \\
\text { (mental assessment); The group points } \\
\text { out the need to involve the family } \\
\text { throughout the entirety of the care } \\
\text { process for the effective control of this } \\
\text { symptom }\end{array}$ \\
\hline Anorexia & $\begin{array}{l}\text { Personal history, in depth interview that } \\
\text { evaluates psycho-social-nutritional aspects, } \\
\text { physical evaluation, body mass index, taking } \\
\text { anthropometric measurements, assessment } \\
\text { of alimentary and nutritional habits that } \\
\text { allow to determine if the anorexia is } \\
\text { voluntary or secondary to a pathological } \\
\text { starvation disorder }\end{array}$ & $\begin{array}{l}\text { Introduce probe of enteral } \\
\text { nutrition or parenteral nutrition, } \\
\text { remission to a nutritionist or a } \\
\text { psychiatrist }\end{array}$ & $\begin{array}{l}\text { Improved nutritional status, recovery } \\
\text { of the nutritional appetite }\end{array}$ \\
\hline Cachexia & $\begin{array}{l}\text { Muscle evaluation (tone, strength and size), } \\
\text { body mass index, skin folds, cutaneous } \\
\text { turgor, anamnesis, physical musculoskeletal } \\
\text { and integumentary assessment }\end{array}$ & $\begin{array}{l}\text { Nutritional assessment to start the } \\
\text { required replacement, avoid } \\
\text { pressure areas by making changes } \\
\text { in position, make curves of mass } \\
\text { and weight gain, promote protein } \\
\text { and calorie intake (depending on } \\
\text { the clinical condition), promote } \\
\text { physical activities according to the } \\
\text { condition (passive exercises) to } \\
\text { avoid further muscle deterioration } \\
\text { or preservation }\end{array}$ & $\begin{array}{l}\text { Assess muscle mass and if necessary } \\
\text { paraclinical to assess micronutrient } \\
\text { levels; assess pressure zones; curve } \\
\text { analysis to identify if the person is } \\
\text { making an adequate contribution; } \\
\text { assessing muscle tone and strength in } \\
\text { order to identify muscular atrophies }\end{array}$ \\
\hline Fatigue & $\begin{array}{l}\text { Perform anamnesis in relation to activities } \\
\text { the person has discontinued, either for their } \\
\text { physical and psychological condition }\end{array}$ & It is not presented & It is not presented \\
\hline Diarrhea & $\begin{array}{l}\text { Frequency, fever, presence of blood, texture, } \\
\text { food, smell, color, gastrointestinal habits, } \\
\text { grade of dehydration, oral tolerance of pain; } \\
\text { Evaluate the use of home remedies and its } \\
\text { relationship with the appearance of the } \\
\text { symptom }\end{array}$ & $\begin{array}{l}\text { Control of vital signs, fluid control, } \\
\text { anti-diarrheal management, } \\
\text { changes in nutrition, } \\
\text { administration of liquids and } \\
\text { electrolytes and weight control }\end{array}$ & $\begin{array}{l}\text { Decreased diarrhea and dehydration } \\
\text { improvement }\end{array}$ \\
\hline Nausea & $\begin{array}{l}\text { Specific anamnesis of the symptom, oral } \\
\text { tolerance and identify drugs that could cause } \\
\text { side effects and/or foods that can cause this } \\
\text { symptom; } \\
\text { It is important to assess environment and } \\
\text { food preparation as trigger factors of the } \\
\text { symptom }\end{array}$ & $\begin{array}{l}\text { Recommend replacing the foods } \\
\text { that cause the nausea and } \\
\text { administer antiemetic }\end{array}$ & $\begin{array}{l}\text { Decreased nausea and restarting the } \\
\text { digestion }\end{array}$ \\
\hline Vomit & $\begin{array}{l}\text { Frequency, color, texture, causes that } \\
\text { generate it, investigate treatment received } \\
\text { (pharmacological and } \\
\text { non-pharmacological), food } \\
\text { preparation and food triggers }\end{array}$ & $\begin{array}{l}\text { Administer antiemetic, modify } \\
\text { diet, fluid control, administer } \\
\text { fluids, weight control }\end{array}$ & $\begin{array}{l}\text { Decreased vomiting and improved } \\
\text { hydration }\end{array}$ \\
\hline
\end{tabular}




\begin{tabular}{|c|c|c|c|}
\hline Ascites & $\begin{array}{l}\text { Anamnesis is done to identify the cause and } \\
\text { physical examination, emphasizing the } \\
\text { abdominal assessment }\end{array}$ & $\begin{array}{l}\text { Diuretics are administered; } \\
\text { determine the need for } \\
\text { paracentesis; abdominal } \\
\text { perimeter control; weight control, } \\
\text { control of administered and } \\
\text { disposed fluids; control blood } \\
\text { pressure. It is important to } \\
\text { promote the patient's mobility and } \\
\text { educate the family about resting } \\
\text { positions }\end{array}$ & $\begin{array}{l}\text { Assess implications for patient } \\
\text { mobility; decreased abdominal } \\
\text { perimeter and feeling of comfort }\end{array}$ \\
\hline Intestinal obstruction & $\begin{array}{l}\text { An Anamnesis focused on the } \\
\text { gastrointestinal system is made: Intestinal } \\
\text { habits, food, presence of abdominal pain and } \\
\text { characteristics, irradiation, with what does } \\
\text { the pain exacerbate or reduce, how long ago } \\
\text { was the last deposition, characteristics, take } \\
\text { medications }\end{array}$ & $\begin{array}{l}\text { Identify the cause of the } \\
\text { obstruction and depending on it, it } \\
\text { is intervened in relation to the diet, } \\
\text { drugs that could possibly cause the } \\
\text { obstruction, pain management, if it } \\
\text { decreased or disappeared or if it } \\
\text { remains }\end{array}$ & $\begin{array}{l}\text { It is assessed whether if the patient } \\
\text { was able to perform depositions }\end{array}$ \\
\hline Itching & $\begin{array}{l}\text { Anamnesis and subjective findings of the } \\
\text { patient, evidence of local redness, injury to } \\
\text { the affected area }\end{array}$ & $\begin{array}{l}\text { Pharmacological treatment taking } \\
\text { into consideration the origin }\end{array}$ & $\begin{array}{l}\text { Manifestation of the cessation of the } \\
\text { symptom and indication of } \\
\text { improvement in the affected area }\end{array}$ \\
\hline Lymphedema & $\begin{array}{l}\text { The students describe not having the } \\
\text { necessary elements for the assessment } \\
\text { of origin }\end{array}$ & $\begin{array}{l}\text { Diuretics administered based on } \\
\text { the pathology and the water } \\
\text { balance }\end{array}$ & $\begin{array}{l}\text { The students describe not having the } \\
\text { necessary elements for the assessment } \\
\text { of the intervention }\end{array}$ \\
\hline Insomnia & $\begin{array}{l}\text { Sleep patterns are evaluated: sleep time, if } \\
\text { sleep is restful; the habits before bedtime are } \\
\text { investigated; food consumed before bedtime; } \\
\text { investigate about taking medication at night. } \\
\text { Activities of daily life that interfere with } \\
\text { sleep }\end{array}$ & $\begin{array}{l}\text { Education about sleep hygiene } \\
\text { habits; assess and design a care } \\
\text { plan and medication } \\
\text { administration that does not affect } \\
\text { sleep; resolve patient concerns that } \\
\text { may interfere with sleep due to } \\
\text { worries; remove the factors that } \\
\text { may be predisposing to disrupt } \\
\text { sleep }\end{array}$ & $\begin{array}{l}\text { An investigation is made to the patient } \\
\text { and the caregiver of post-intervention } \\
\text { if the sleep was restful and positive or } \\
\text { negative in changes of the sleeping } \\
\text { patterns }\end{array}$ \\
\hline Delirium & $\begin{array}{l}\text { Assessment of guidance, time and space, } \\
\text { bearing and attitude, judgment and } \\
\text { reasoning, sleep pattern and investigate } \\
\text { about what object or person is causing the } \\
\text { anxiety }\end{array}$ & $\begin{array}{l}\text { Perform an interdisciplinary work } \\
\text { to recognize and act on the issues } \\
\text { that affect their mental health. } \\
\text { Intervene with drugs if necessary }\end{array}$ & $\begin{array}{l}\text { A post-interventions assessment is } \\
\text { made to observe the obtained } \\
\text { achievements, assess whether the } \\
\text { medication is the appropriate one, } \\
\text { verify if every professional is fulfilling } \\
\text { their duties }\end{array}$ \\
\hline Anxiety & $\begin{array}{l}\text { The reactions of the person to the situation } \\
\text { are evaluated; presence of Insomnia } \\
\text { conciliation, tachycardia, diaphoresis, } \\
\text { verbiage and psychomotor agitation }\end{array}$ & $\begin{array}{l}\text { Collaborate with the relaxation; } \\
\text { identifying the cause; allow the } \\
\text { expression of feelings; administer } \\
\text { anxiolytics if required; educating } \\
\text { the patient and his family, establish } \\
\text { support networks with psychology }\end{array}$ & $\begin{array}{l}\text { Gain control of the symptoms } \\
\text { associated with anxiety; Improve } \\
\text { mood, control insomnia, psychomotor } \\
\text { agitation and vital signs }\end{array}$ \\
\hline Depression & $\begin{array}{l}\text { The isolation is assessed, crying easily, } \\
\text { suicidal ideation, early awakening insomnia, } \\
\text { hyporexia, weakness in judgment }\end{array}$ & $\begin{array}{l}\text { Identify the cause, } \\
\text { psycho-education, } \\
\text { communication, Assertive, manage } \\
\text { pharmacological treatment and } \\
\text { search for family and institutional } \\
\text { support networks }\end{array}$ & $\begin{array}{l}\text { Improve the mood and the associated } \\
\text { symptoms }\end{array}$ \\
\hline
\end{tabular}


Research has shown that a systematic evaluation of the attention given allows a better control of symptoms, an increase in the quality of care, the proper use of health resources, the increase in the supportive care and greater education for the patient and his family [14]. With the gathered results it can be inferred that the participants have a tendency to evaluate their interventions depending on the level of improvement or the complete resolution of the symptom, without taking into consideration the implications about the patient's quality of life, their prognosis and survival profile. The previous could trigger the abandonment of interventions, by failing to fulfill the expectations of health recovery posed by the nursing student. On the other hand, the students recognize that the vital signs give them an idea of the health situation and the patient's prognosis, even in cases of mental sphere symptoms, which warns about the need to contextualize the control of these parameters of biological functions considering the general situation of the patient.

\subsection{Identification of Capabilities to Take on Specific Skills in Palliative Care}

Following the skills defined by Redcoledupal, the students selected from the full list of skills for the nursing training in palliative care, those considered to be relevant in the care of people in conditions of advanced or terminal disease. The first subject area of skills, "definition and principles of palliative care" is structured by three skills of which the student groups that participated in the research consider they are able to: support the palliative care of people from the conceptual models of nursing care (5 groups), understand hospice philosophy and know the principles and history of palliative care (2 groups) and define palliative care, its philosophy and basic principles (1 group).

Regarding "identification and management of symptoms", the identified skills are related to detecting the needs of nursing care for the control of symptoms in advanced and/or terminal diseases (5 groups), develop skills for the safe subcutaneous administration of medication (4 groups), recognize the pharmacological and non-pharmacological principles for the management and control of the symptoms (4 groups), develop skills for using rating scales in palliative care (2 groups), identify the signs of the last days of life situation and be able to apply specific care associated with this phase of the disease ( 3 groups). For this domain, neither of the groups recognizes of being able to identify the most common symptoms associated with advanced or terminal diseases and know the appropriate measures to detect, control, or soothe the clinical problems and the common, urgent situations that occur in the advanced phase of the disease.

In the area of "psychosocial aspects and support networks", the assumed competencies are to develop skills in transcultural care to identify the involvements that are religious, cultural, values and beliefs of the patient and his family in the face of terminal disease and death (4 groups), recognize the most frequent nursing interventions in the family situation with a patient in palliative handling to limit the appearance of family claudication (2 groups), identify patient and 
family resources to cope with the advanced and/or terminal disease (2 groups), identify coping strategies against the presence of death (1 group) and recognize the adaptive reactions of the patient and his family against the situation of terminal disease (1 group).

Regarding "communication in palliative care", the groups recognize competencies such as the ability to develop communication skills for bad news to guarantee the therapeutic relation ( 3 groups) and identify the nurse's responsibilities in the care of people who require palliative care, as well as the primary caregiver and his family (1 group). On the other hand, for "ethical and legal aspects" the students point out their ability to recognize public policies related with palliative care in the country (4 groups) and elaborate clinical records (initial evaluation, nursing diagnosis, interventions and care plans) according to the conditions of the patient and his family (6 groups).

About the "teamwork and personal reflection", the students consider to be able to recognize the importance of collaborative work with other professionals to improve the quality of nursing care (6 groups) and design, plan, execute and evaluate programs and nursing care plans based on trans-disciplinary decisions regarding the care for patients and their families in a terminal situation (5 groups). In the case of "implementation of palliative care services", the groups consider to be able to identify the current situation of development and the implementation of palliative care internationally (3 groups), identify basic tools for risk management in palliative care programs and services ( 3 groups), recognize the palliative care levels, organization of resources and types of organizational structures in palliative care (2 groups) and know the organizational model of palliative care units at a general level (1 group). No group was able to recognize and apply basic quality indicators in a palliative care program.

\subsection{Implications for Education in Nursing}

The narratives of the participants of the research allow us to identify the notions about palliative care according to seven subject areas in this field of knowledge. There is a capacity of building well-founded concepts about palliative care and suffering. However, when that capacity was confronted with the skill to define palliative care, it's philosophy and basic principles there is no established relationship between what is conceptually presented and the ability to operationalize the concept. Regarding the decision making for cases involving ethical tensions, the participants argue for nursing interventions, using ethical and legal concepts, as well as the clinical judgment of particular situations of people and families with palliative needs.

As for the family approach to palliative care, student's address not being able to recognize family claudication, however, some groups recognize interventions for the prevention of this syndrome. The inconsistency attracts attention regarding the capacity to identify the support networks, given that in the case analysis all the groups clearly identify personal and family support networks. As for the appropriation of the spirituality component, none of the groups recog- 
nize this dimension, which could be significant in strengthening its implementation in the training practice of nursing curriculums.

In the development of communication skills in palliative care, there is an appraised strength in the role game activity, on the contrast of the capacity to recognize the development of skills to communicate bad news and the nursing role in the care of people that need palliative care, which shows the need to consolidate the relationship between the theoretical knowledge and the practical training experiences of the nursing role in this type of care situations.

There is a marked emphasis for the evaluation and management of the physical symptoms, with a poor recognition of the psychological and social symptoms. In consideration to the competencies, it attracts attention that none of the participant groups express to identify the most commons symptoms in palliative care, or know the steps to intervene in situations of an advanced stage of the disease. This indicates a specific need in nursing education for the identification and management of symptoms of advanced and/or terminal diseases.

Nursing education requires the determination of an approach in which the students will be capable of caring for people with palliative needs. Universities need to analyze their curriculums to include content and direct them toward the formation in palliative care; this does not necessarily involve curriculum modification, but the revision of micro-curriculums to show specific content of this area of care in the subjects related with the final phase of life, family, communication, spirituality, support networks and the nursing care plan for patients with symptoms derived from advanced and/or terminal diseases.

\section{Conclusions}

The participating students have notions in some of the subject areas addressed in this study. A conceptual development, in the definition and the principles of palliative care, in understanding the regulations, support networks and ethical aspects for decision-making is shown. If the nursing role is considered in the care of a person with palliative needs, the level of conceptual construction achieved by the students, would not allow the approach of a person in a condition of an advanced disease, given that palliative care requires the integral intervention of physical, psychological, social and spiritual needs.

The participants in the study have strength in identifying support networks, in recognizing the importance of collaborative work, and the elaboration of clinical records for people with an advanced disease, in detecting the needs of nursing care to control symptoms and in designing trans-disciplinary attention programs and plans for the patient care. The opportunities for knowledge consolidation are related to the identification of common symptoms in the advanced disease, as well as the appropriate measures for its operation. Other aspects to consolidate refer to the recognition of the organization of palliative care services, the comprehension of adaptive reactions of the patient and his family facing the disease, the identification of coping strategies for death and the identification of 
nurse's responsibilities in palliative care.

\section{Limitations}

Due to the particularities of this study, especially because it is a research project in the university's classroom, the results of this study can only be interpreted with similar degree courses, and which the educational process as well as the institutional characteristics are also similar to those which took place in this study.

\section{Conflicts of Interest}

The authors declare no conflicts of interest regarding the publication of this paper.

\section{References}

[1] Sulmasy, D.P. (2002) A Biopsychosocial-Spiritual Model for the Care of Patients at the End of Life. The Gerontologist, 42, 24-33. https://doi.org/10.1093/geront/42.suppl_3.24

[2] Codorniu, N., Bleda, M., Alburquerque, E., Guanter, L., Adell, J., García, F. and Barquero, A. (2011) Cuidados Enfermeros en Cuidados Paliativos: Análisis, Consensos y Retos [Nursing Care in Palliative Care: Analysis, Consensuses and Challenges]. Index de Enfermería, 20, 71-75. https://doi.org/10.4321/S1132-12962011000100015

[3] Martins, P.S. and Hernández-Marrero, P. (2016) Palliative Care Nursing Education Features More Prominently in 2015 than 2005: Results from a Nationwide Survey and Qualitative Analysis of Curricula. Palliative Medicine, 30. https://doi.org/10.1177/0269216316639794

[4] Restrepo Gómez, B. (2009) Investigación de Aula: Formas y Actores. Revista Educación y Pedagogía, 21.

[5] Löfström, E., Nevgi, A., Wegner, E. and Karm, M. (2015) Images in Research on Teaching and Learning in Higher Education. Theory and Method in Higher Education Research, 1, 191-212. https://doi.org/10.1108/S2056-375220150000001009

[6] Vitillo, R. and Puchalski, C. (2014) World Health Organization Authorities Promote Greater Attention and Action on Palliative Care. Journal of Palliative Medicine, 17, 988-989. https://doi.org/10.1089/jpm.2014.9411

[7] Ballesteros, J., Santos, B., González-Fraile, E., Muñoz-Hermoso, P., Domínguez-Panchón, A.I. and Martín-Carrasco, M. (2012) Unidimensional 12-Item Zarit Caregiver Burden Interview for the Assessment of Dementia Caregivers' Burden Obtained by Item Response Theory. Value in Health, 15, 1141-1147. https://doi.org/10.1016/j.jval.2012.07.005

[8] Borneman, T., Sun, V., Williams, A.C., Fujinami, R., Del Ferraro, C., Burhenn, P.S. and Buga, S. (2015) Support for Patients and Family Caregivers in Lung Cancer: Educational Components of an Interdisciplinary Palliative Care Intervention. Journal of Hospice \& Palliative Nursing, 17, 309-318. https://doi.org/10.1097/NJH.0000000000000165

[9] Barnum, B.S. (2006) Spirituality in Nursing: From Traditional to New Age. Springer, Berlin.

[10] Lenz, E.R., Pugh, L.C., Milligan, R.A., Gift, A. and Suppe, F. (1997) The Middle-Range Theory of Unpleasant Symptoms: An Update. Advances in Nursing Science, 19, 14-27. https://doi.org/10.1097/00012272-199703000-00003 
[11] Marriner-Tomey, A. and Alligood, M.R. (1997) Nursing Theorists and Their Work.

[12] Ahtisham, Y. and Jacoline, S. (2015) Integrating Nursing Theory and Process into Practice; Virginia's Henderson Need Theory. International Journal of Caring Sciences, 8, 443-450.

[13] Bulechek, G.M., Butcher, H.K. and Dochterman, J.M. (2008) Nursing Interventions Classification (NIC).

[14] Ashley Varner, M.S.W. (2014) The Development of a Nursing Assessment and Symptom Management Clinic. Clinical Journal of Oncology Nursing, 18, 12-16. https://doi.org/10.1188/14.CJON.S2.12-16 